\title{
A gramática a serviço do desenvolvimento da escrita
}

\author{
Edilaine Buin
}

UNICAMP

Este trabalho discute as condições atuais de ensino de língua portuguesa e, baseado nos Parâmetros Curriculares Nacionais (PCN), propõe uma metodologia de ensino de língua materna cujas aulas de gramática estejam a serviço do desenvolvimento da escrita. Para isso, analisa uma redação narrativa de uma aluna de $5^{a}$ série do Ensino Fundamental II da rede pública do Estado de São Paulo, com ênfase no uso pronominal, e, a partir dessa redação, sugere um encaminhamento para as aulas de gramática. Trata-se de uma tentativa de aliar a teoria lingüística de ensino de língua materna à prática docente.

This research work presents a discussion of the current conditions of Portuguese Language Teaching, also suggesting a methodology of First Language Teaching based on the guidance of the National Curricular Parameters (Parâmetros Curriculares Nacionais), in which grammar classes assist the development of writing. In order to do that, the use of pronouns is analyzed particularly, in a composition of narrative style written by a Middle School student from a public school in the state of São Paulo, Brazil. Starting from this analysis, the conduction of the student to grammar classes is suggested. This is an attempt to ally the Linguistics Theory of First Language Teaching to the Teacher's practice.

(...) a gramática tradicional pode ser o ponto de partida de hipóteses fecundas, que elaboramos com freqüência a partir de seus exemplos e das passagens confusas que ela teoriza sobre fatos da lingua. (...) nesse papel a gramática tradicional é riquíssima - tão rica quanto nossa capacidade de explorá-la. Aqui como albures a tradição nos fornece imagens esteriotipadas: o mal não está em trabalhar com elas (o que é inevitável) mas em ficar apenas com elas, esquecendo a realidade que deveriam, supostamente, representar. Sucumbir a esse risco é sempre um desastre, mesmo e principalmente quando traz o conforto de parecer integrado.

ILARI, 1992, p. 43/44. 


\section{Introdução}

Muitos lingüistas apontam hoje os problemas do ensino de gramática normativa, alguns dos quais exemplificaremos muito brevemente neste trabalho. Reforçaremos aqui a ineficácia do sistema de ensino de português ainda hoje, uma vez que fatos nos mostram que parte considerável dos alunos saem do segundo grau sem dominar os recursos que poderiam auxiliá-los a se expressar com eficiência e adequadamente por escrito. Depoimentos de professores de terceiro grau revelam a dificuldade da maioria em se expressar por escrito: alunos que vieram não só de escolas públicas, como também de particulares.

O principal objetivo da escola, que é o de que os alunos tenham competência para escrever e ler, não está sendo alcançado. Fatores psicológicos e socioeconômicos podem interferir na aprendizagem. No entanto, a incidência de fracassos em relação à capacidade de expressão escrita pode ser um forte indício de que o sistema escolar de forma geral não tem contribuído para o seu aperfeiçoamento.

Este trabalho descreve e aponta alguns problemas recorrentes na escola, especificamente no Ensino Fundamental II, relacionados ao ensino de Língua Portuguesa e, a partir desses problemas, propõe uma metodologia alternativa para o ensino, fundamentada nos Parâmetros Curriculares Nacionais (PCN). Utiliza-se para análise uma redação escolar de uma aluna de $5^{\text {a }}$. série do Ensino Fundamental.

\section{O ensino de Língua Portuguesa}

Na escola se aprendem nomes, não se aprendem as coisas a que eles se referem.

Rubem Alves, 2003.

O que é comum na maioria das escolas é o ensino da chamada gramática tradicional ou normativa. O professor segue tópicos de conteúdos relacionados à Morfologia e à Sintaxe. Os alunos ouvem a explicação, geralmente em uma aula de caráter teórico e, a partir dessa aula, realiza-se uma série de exercícios de fixação. São os pontos gramaticais que figuram em programas escolares e em manuais didáticos. Por exemplo, ensinam-se os tipos de sujeito, tipos de predicado, tipos de verbos e os alunos são expostos a diferentes frases para realizar a chamada análise sintática. A proficiência do aluno diz respeito ao uso 
da metalinguagem e à identificação de categorias de análise que não vão além da gramática da frase. Geralmente frases que não fogem muito do que a teoria aborda, considerando-se poucas exceções às regras. Alguns professores dizem aplicar a gramática ao texto, o que, na prática, significa destacar alguns períodos de um texto maior e aplicar a mesma abordagem. O objeto de ensino é a retenção da nomenclatura e das categorizações extraídas da gramática tradicional.

Por exemplo, ao abordar pronomes, a gramática tradicional classificaos em possessivos, demonstrativos, relativos, indefinidos, interrogativos. A seguir, propõe exercícios baseados em frases e enunciados, muitas vezes criados apenas para tal fim. Neves (2004) observou que os livros didáticos retiram frases de um texto e pedem para o aluno substituir o nome por um pronome. Esse tipo de exercício ilustra, segundo a autora, um desperdício do tempo que é gasto na resolução porque, no texto de onde as frases foram retiradas, não caberia tal substituição, ora porque alteraria o sentido, ora porque se perderia a referência devida. A autora também observa que a referência ao sujeito ou objeto por elipse (que tem função de pronome pessoal) é totalmente desconsiderada nesses livros. São muito mais raras atividades que requerem alguma reflexão sobre o uso pronominal em textos e a resolução de uma série de exercícios não garante que o aluno faça uso do pronome de uma maneira adequada quando produz um texto.

Embora alguns acreditem que sim, a aula de gramática tradicional, embora possa gerar algum tipo de reflexão sobre o funcionamento da língua, parece não estar contribuindo de forma eficaz para o aperfeiçoamento da leitura e da escrita do aluno. Um aluno que tenha um desempenho muito bom em gramática não terá necessariamente um bom desempenho em produção de textos. Da mesma forma, excelentes escritores podem não entender nada de gramática tradicional.

Em algumas escolas particulares, as aulas de gramática são ministradas, tanto no ensino fundamental quanto no médio, com mais recorrência neste último, por um único professor que se difere daquele que trabalha com interpretação de textos, literatura e redação. Apesar de relacionadas ao ensino de língua materna, são disciplinas independentes. Quando esses conteúdos são ministrados pelo mesmo professor, ainda assim são independentes, com raras exceções.

Cabe ressaltar aqui que o modelo de Vestibular Unicamp, a partir de 1987, com a intenção de mudar o perfil do aluno que ingressava nessa 
universidade, inseriu a redação na primeira fase seletiva, como sendo uma indicadora da capacidade de leitura, escrita e crítica do aluno, independentemente do curso em que ele estava inscrito. O contato com escolas da região de Campinas tem apontado a importância que a produção de textos ganhou nesse modelo seletivo, que, segundo depoimentos de professores e coordenadores, mudou a história de ensino de língua nas escolas voltadas para o vestibular, à medida que passaram a incentivar os alunos a escrever com mais freqüência. De forma geral, os alunos passaram a escrever mais. Isso é muito positivo. No entanto, a escola precisa oferecer um pouco mais que proporcionar o treinamento.

Identificam-se, então, dois tipos de trabalho com a língua: aula de gramática tradicional totalmente independente de redação, ou aulas de interpretação de texto e redação e nenhuma abordagem gramatical. Tanto um jeito como outro não permite que a escrita dos alunos evolua de forma objetiva, sistemática e eficiente, ou seja, a escrita dos alunos não evolui além daquilo que o próprio treino naturalmente proporciona.

São numerosos os lingüistas que criticam o ensino de português em geral. Perini (2000), por exemplo, insiste em que os objetivos da matéria estão mal colocados e aponta incoerências internas da Gramática Tradicional. Segundo o autor, "deve-se estudar gramática para saber mais sobre o mundo; não para aplicá-la à solução de problemas práticos como ler ou escrever melhor" (p. 55).

O que se observa não é a falta de crítica a esse tipo de ensino, mas a falta de uma metodologia que permita aos professores ensinar a língua materna de outro modo. Alguns menos tradicionais até percebem a "ineficácia" do sistema, mas não conseguem ter existência fora dele ou têm dificuldades para desenvolver uma outra metodologia.

\section{Os Parâmetros Curriculares Nacionais}

A língua é como é, não como deveria ser.

Perini, 1997.

O ensino de gramática tem sido abordado da maneira como expusemos acima, apesar de os Parâmetros Curriculares Nacionais (PCN), inspirados nos autores que criticam a maneira tradicional, apontarem para outra direção. 
Silva (2003) faz um estudo dos PCN, cuja proposta de ensino de língua portuguesa é explicitada como uma resposta às críticas que foram feitas ao ensino tradicional. O autor retoma algumas críticas contidas nos PCN. Uma delas, quanto ao uso que se faz do texto como pretexto para o ensino tradicional da gramática; a outra, em relação ao ensino prescritivo, que impossibilita a reflexão sobre os usos da língua, pois só a variedade padrão é alvo de análise.

O principal objetivo de Língua Portuguesa, segundo os PCN, é o desenvolvimento da competência discursiva do discente. Para alcançar esse objetivo, a orientação é a de que o texto seja a unidade de ensino. Como ele se submete às regularidades lingüisticas dos gêneros em que se organiza e as especificidades de suas condições de produção, há necessidade de se priorizar alguns conteúdos e não outros. Assim, a sistematização do conteúdo a ser trabalhado será apontada pelo próprio texto proposto para leitura ou produzido pelo aluno.

Os PCN vão priorizar uma abordagem aleatória ou assistemática da gramática, uma vez que os conteúdos devem ser abordados de acordo com as necessidades apresentadas pelos alunos em função das atividades de produção, leitura e escuta dos textos. Nessa perspectiva, o gênero do texto é que deve ser a unidade temática e não mais os tópicos gramaticais. Silva (2003, p.41) conclui que

as atividades inerentes ao eixo de reflexão sobre a língua dos PCN seguem o mesmo princípio da abordagem da teoria dos gêneros textuais dos estudos funcionalistas da linguagem (...) que objetivam trazer o conhecimento cultural intuitivo dos usuários da língua para o consciente deles.

Conforme postulam Schneuwly \& Dolz (1999, p. 7), os gêneros devem funcionar como um mega-instrumento que fornece um suporte para a atividade na situação de comunicação e uma referência para os aprendizes. Vale destacar, assim como o fez Silva (2003, p. 42-43), o seguinte trecho dos PCN:

Tomando como ponto de partida o texto produzido pelo aluno, o professor pode trabalhar tanto os aspectos relacionados às características estruturais dos diversos tipos textuais como também os aspectos gramaticais que possam instrumentalizar o aluno no domínio da modalidade escrita da língua. (PCN, p. 80). 
Orientando o trabalho gramatical para uma prática reflexiva e conscientização crítica sobre a funcionalidade dos elementos lingüísticos em diferentes gêneros, ou seja, em textos de diferentes formas de ação social, os PCN se aproximam muito da abordagem funcional da gramática. Ao contrário do que as escolas têm feito, que é usar o texto como um ilustrativo dos tópicos gramaticais ou como um recurso para leitura e interpretação totalmente independente das aulas de gramática, destacaremos a abordagem de uma gramática a serviço do aprimoramento da escuta, da leitura e, especificamente neste trabalho, da escrita.

\section{O encaminhamento das aulas de gramática a partir da correção do texto ${ }^{1}$}

Ao se optar por partir da produção de texto, a atividade de correção assume importância fundamental para o encaminhamento dos conteúdos gramaticais. Ao invés de uma correção restrita à identificação de erros pontuais, o professor-corretor assume o papel de leitor atento do texto do seu aluno, interessado em compreender o que o aluno tem a dizer e ajudá-lo a melhorar, ou seja, encontrar recursos lingüísticodiscursivos necessários naquele caso específico. O procedimento evidenciado como adequado é o de apontar e classificar os problemas de modo a orientar o aluno na busca de soluções para a refacção de seu texto e, assim, iniciar uma seqüência de procedimentos de reescrita com vistas ao aprimoramento dos recursos apropriados pelo aluno, em função dos efeitos de sentido que ele deseja produzir.

De acordo com Signorini et alii (2004), a leitura do professor deve ser realizada de modo a focalizar três níveis interrelacionados: em um primeiro momento o nível macro de adequação do texto ao gênero escolhido, em um segundo momento o nível micro das construções frásticas e o terceiro nível do uso das convenções gráficas. O nível macro compreende aspectos relacionados à coerência textual global: a organização do texto, a relação entre as partes, a construção do fio temático, o grau de completude. Problemas nesse nível devem ser

\footnotetext{
${ }^{1}$ O que vem descrito nesta sessão foi desenvolvido no projeto Teia do Saber, curso voltado para professores do ensino fundamental II, coordenado pela Profa. Dra. Inês Signorini.
} 
apontados através da escrita de bilhetes indicativos para o aluno, cujo objetivo é o de orientá-lo na primeira refacção.

O nível micro compreende aspectos relativos à morfossintaxe, às marcas dialetais, à coesão interfrástica e intersintagmática. No terceiro nível, entra o uso das convenções gráficas: a ortografia, a pontuação, a paragrafação, a disposição do texto na página, etc. Problemas nesses dois últimos níveis devem ser apontados no texto do aluno e/ou classificados através de sinais indicativos, conhecidos do aluno (RUIZ, 2001). O objetivo da correção continua sendo o de orientar o aluno na segunda reescrita de seu texto.

Em função da leitura e análise do texto reescrito do aluno, o professor terá elementos para identificar os problemas remanescentes e que precisam ser abordados de forma mais sistemática, inclusive as questões gramaticais que devem ser estudadas em sala de aula. Isso porque os problemas identificados ao longo do processo de reescrita do texto do aluno vão orientar o professor na elaboração de um diagnóstico mais confiável do que o aluno já sabe e do que precisa aprender. Esse diagnóstico se configura como uma avaliação não só da escrita do aluno, mas também das estratégias e conteúdos de ensino. Nesse sentido, é um subsídio necessário para o planejamento do programa de ensino do professor, pois deve orientar a elaboração de atividades e a escolha de exercícios que enfoquem os problemas recorrentes, de maior incidência na escrita de seus alunos.

Assim, os tópicos gramaticais são eleitos não mais de forma descontextualizada, como quando se usa o texto como um pretexto para o estudo de pontos gramaticais em frases isoladas, mas em função das necessidades detectadas nas produções dos alunos ou nas atividades de leitura. Esse é o objeto de ensino da tão falada gramática do texto: o estudo dos recursos que estão a serviço de determinado gênero que o aluno quer/precisa dominar.

Ilari (1997) sugere que, quando o objetivo é o aprimoramento da escrita, ao invés de aula de gramática tradicional, o que interessaria é aula de "teoria do texto" ou "teoria do discurso", ou seja, a coesão interna e a adequação a uma situação. O que se defende neste trabalho não é a eliminação de aulas de gramática na escola, mas a aula de gramática contextualizada (que Ilari chama de "teoria do texto"), sob a perspectiva funcionalista (HALLIDAY, 1985). Ainda que o objetivo do ensino de 
gramática seja a reflexão sobre a língua e não o aprimoramento da escrita, como se pode refletir sobre uma língua delimitando-se à análise de frases e períodos e não de textos em sua completude?

Isso tudo pressupõe aulas de gramática cujo objetivo seja estender a competência do falante/escritor à organização das peças de interação. Um espaço adequado para isso é a atividade de reescrita, que requer uma co-autoria. A forma como é feita a correção da redação é muito significativa, pois é ela que vai propiciar ou não esse movimento.

\section{Sugestões metodológicas e um exemplo de uma redação²}

O objetivo de mostrar aqui uma redação escolar é o de propor um redirecionamento para uma atividade escrita existente nas escolas, ilustrando de forma mais próxima da prática vigente do professor o que se está teorizando. Antes de considerar os aspectos formais de organização textual, a fim de se propor um trabalho visando à aula de gramática, é muito importante refletir primeiramente sobre o contexto de produção da redação.

De acordo com os PCN, a atividade escolar de produção de textos, entre outras, deve estar aliada às práticas sociais da vida cotidiana nas quais os alunos estejam engajados ou possam vir a se engajar. Assim, gêneros como narração escolar ou dissertação escolar, por exemplo, não são considerados nesse documento, pois o objetivo da produção é o cumprimento de tarefa, tanto por parte do discente quanto do docente. O primeiro escreve para o segundo ler e avaliar. O professor corrige para atribuir uma nota ou porque considera os apontamentos que faz importantes para o aperfeiçoamento da escrita (e realmente devem ser). Para ambos, a atividade de escrita e correção resume-se a uma tarefa escolar, quando o ideal seria a preocupação do texto estar "correto" porque, exercendo uma função social, será lido

\footnotetext{
${ }^{2}$ Esta redação foi produzida por uma aluna de $5^{\text {a }}$. série de uma escola da rede estadual de Campinas, durante o segundo semestre de 2003, e foi fornecida juntamente com outras por uma professora que participava do projeto Teia do Saber, curso de aperfeiçoamento destinado aos professores da rede pública do Estado de São Paulo, Brasil. Trata-se de uma das produções de texto que foi objeto de reflexão durante o curso e possibilitou um encaminhamento do trabalho gramatical, tal como acreditamos ser importante para o desenvolvimento da escrita.
} 
por outras pessoas. Entretanto, é possível que a conhecida narrativa escolar ganhe um sentido social. A chave para isso é que as produções dos alunos sejam lidas entre eles, façam parte de um exemplar de narrações a ser distribuído para alunos de outras turmas ou para a comunidade, em um evento comemorativo, em forma de livro, de revista ou de uma simples coletânea, dependendo das condições financeiras da escola, por exemplo.

Em séries escolares menos avançadas, como a $5^{\text {a }}$. série do Ensino Fundamental, o professor de português, em conjunto com o de artes, pode orientar os alunos na decoração da capa de um caderno pequeno brochura, para que seja "bonito" e "especial". Nesse caderno, os alunos deixam um espaço na primeira página para uma futura dedicatória, pois no final do ano vão escolher a pessoa para quem o material será oferecido e/ou presenteado. Ao longo do ano, passam a limpo todas as "histórias" escritas e corrigidas pelo professor; sempre sendo lembrados que os textos que estiverem ali deverão ser lidos por alguém muito especial a ser escolhido por eles. Minha experiência como professora permite dizer que isso muda a relação do aluno com a escrita: eles redigem a última versão com muito mais entusiasmo e capricho, pois essa atividade tem uma função que extrapola o universo de tarefa escolar. Essa atividade parece estar de acordo com a concepção de linguagem assumida pelos PCN que, como lembra Silva (2003, p. 40), demonstram a influência dos estudos de Bakhtin (2002, 2000) em seus postulados teóricos:

ação individual orientada por uma finalidade específica, um processo de interlocução que se realiza nas práticas sociais existentes nos diferentes grupos de uma sociedade, nos diferentes momentos de sua história (p. 20).

Os estudos aplicados de linguagem (cf. BRONCKART, 1999; ROJO, 2000; SCHNEUWLY \& DOLZ, 1999, dentre outros), conforme retoma Silva (2003, p. 41), concebem os gêneros como "ferramentas semióticas que permitem a construção da identidade do discente na prática de escrita, bem como a criação de uma situação nova para aprender novas formas de produzir, interpretar e agir". Sob essa perspectiva, trabalhar a escrita da narrativa, não mais como uma redação escolar, mas como um "gênero narrativo" (como parte de um conjunto de outras atividade de leitura, interpretação e escuta, relacionadas ao mesmo gênero) é, além de reconstruir o texto considerando os aspetos gramaticais de 
forma engajada, também contribuir para a construção da identidade do sujeito na escrita.

A redação apresentada aqui foi produzida no ambiente escolar e fornecida por uma professora da rede pública de Campinas, que desejava orientações no encaminhamento do seu trabalho. Ressalvase a importância de considerar o contexto em que a narrativa foi produzida (para quem se escreve e com que objetivo). Caso o texto venha a não se limitar a uma atividade escolar, a produção do aluno provavelmente vai se aprimorar em relação à coerência; parte dos problemas gramaticais podem ser resolvidos naturalmente à medida que o aluno reescreve consciente da presença de um interlocutor (nesse processo evolutivo, porém, outros novos problemas podem surgir).

O texto foi selecionado entre outros de alunos da mesma série. O critério foi utilizar um que representasse os problemas mais recorrentes daquele conjunto. O mesmo critério pode ter o professor ao selecionar um texto de aluno para um trabalho gramatical mais sistemático.

O cachorro abandonado

Um dia eu encontrei um cachorro perto da minha casa eu chorei de dó eu queria que minha mãe levace ele para minha casa mais ela não quis. Eu vi o cachorro comendo lixo na lixeira e fiquei com muita vontade de levar ele para minha casa mais minha mãe não deixou pois eu tinha que ter muita responsabilidade com ele.

E um dia eu achei uma tartaruga na rua e levei para casa minha mãe falou que se eu cuidace bem dela ela deixaria eu ter um cachorro.

Eu via os cachorros na rua e com uma vontade de levalo para casa eu pedia para minha mãe, ela não deixava, daí eu cuidei bem da tartaruga. Mas veio o dono dela e pegou ela de volta. Eu fiquei triste mas no outro dia eu fui a escola e quando cheguei tinha um lindo cachorro me esperando era um pastor capa 
preta, dei o nome dele de Athila e ele está comigo até hoje.

Fim.

P., $5^{\text {a }}$. série

O texto acima apresenta problemas de pontuação, principalmente o uso do ponto final na construção de períodos mais curtos; de uso de conectores interfrásticos; de ortografia; de escolha das expressões anafóricas. Ilustra também que algumas questões gramaticais estão muito ligadas a questões de sentido. Quando P. diz Eu via os cachorros na rua e com uma vontade de levalo para casa, o cachorro a que se refere o pronome (l)o é o mesmo do primeiro parágrafo, referido respectivamente por um cachorro - o cachorro - ele - ou se trata de outro? O título da redação, que se refere a um cachorro específico, $O$ cachorro abandonado, pode indicar que se tratava do mesmo. Caso essa hipótese esteja correta, o final da narrativa desviou totalmente do início e do desenvolvimento, pois o cachorro abandonado não foi mais mencionado e surgiu um pastor capa preta.

Como o uso do pronome requer uma abordagem que vai além da própria frase da qual ele faz parte, a análise desse elemento coesivo deve estar atrelada ao texto do qual ele também faz parte. Isso pode parecer óbvio, mas não o é quando atentamos à forma como tradicionalmente se interpreta um texto, na perspectiva de que a língua é um sistema de formas, nas quais os significados estão atrelados. A questão que permeia essa concepção de língua é, segundo Halliday (1985, p. xiv), what do these forms mean $?^{3}$ Na perspectiva funcional, a interpretação de um texto segue o caminho inverso. Para Halliday (op. cit.), a língua é interpretada como um sistema de significados, acompanhados de formas através das quais podem se realizar. Tal concepção teria como pano de fundo a questão bow are these meanings expressed? ${ }^{4}$

A reflexão a partir do uso que a aluna fez do pronome deve estar atrelada à reflexão sobre o encadeamento e da coerência do texto. Visando à aprendizagem efetiva (e não apenas uma correção esporádica), não basta destacar o pronome grifando-o ou anexando a

${ }^{3}$ O que essas formas significam? (tradução livre)

${ }^{4}$ Como esses sentidos/significados são expressos? (tradução livre) 
ele um ponto de interrogação ou ligá-lo visualmente à cachorros, destacando a falta de concordância (que a aluna pode não identificar, uma vez que pode estar imaginando um referente para esse elemento não especificado por escrito). Em suma, não basta perguntar "o que (l)o significa?"; a questão que se faz, nessa perspectiva, é "como o pronome deve aparecer para o leitor saber que se refere ao cachorro abandonado, do qual se fala no primeiro parágrafo, ou como deve aparecer para o leitor saber que se refere a qualquer outro cachorro? Como vemos, corrigir o uso pronominal inadequado, na redação de P., significa também mudar o título do texto (caso o pronome se referira a qualquer cachorro) ou o seu desfecho (caso o pronome se refira ao cachorro abandonado específico). Como se observa, não se trata de um problema de não uso do oblíquo, ou de colocação indevida na cadeia sintática, e sim de referência na cadeia anafórica. Trata-se, portanto, de um problema de coerência.

Pensando primeiramente na funcionalidade dos elementos coesivos, a correção deve se iniciar pelo nível macro, pois, às vezes, um apontamento em um problema macro (de encadeamento, de coerência) já resolve o problema micro (gramatical). O recurso que vimos como viável para esse procedimento é a escrita de bilhetes indicativos para os alunos, cujo objetivo é orientar a primeira refacção de seu texto. Esse recurso, além de levar o aluno a refletir primeiramente sobre os significados do texto que produziu, auxilia um professor leitor atento a esse texto, ajudando tanto discente quanto docente a não excluir, em nome da atividade escolar, o processo interativo através do qual o próprio texto ganha sentido.

Como explica Signorini et alli (op. cit.), o professor deve se mostrar um leitor interessado em compreender o que o aluno/ escrevente tem a dizer e também empenhado em ajudá-lo a melhorar o seu texto. Um bilhete produzido para a redação em análise foi:

P: Você começa bem o texto, apresentando para o leitor a situação do cachorro da rua e o desejo de levá-lo para casa. No entanto, o cachorro de que você fala no $3^{\circ}$. parágrafo (lo) é o mesmo do primeiro, aquele que estava comendo lixo, ou é um entre tantos outros que você viu na rua, os quais você menciona no $3^{\circ}$. parágrafo (os cachorros)? Se o título da sua história é "O cachorro abandonado", porque no final a personagem fica com um pastor capa-preta, que não estava abandonado? Ou a sua história é de uma menina que queria muito um cachorro? Reescreva seu texto, deixando isso mais claro para o leitor. 
A partir do bilhete, a reescrita pode vir com o problema pronominal resolvido ou não. Além disso, pode apresentar algumas resoluções ou outros novos problemas. De qualquer forma, o aluno terá tido a chance de resolver algumas questões gramaticais através da reflexão sobre o sentido, sobre a coerência de seu texto. Além disso, terá tido a oportunidade de refletir sobre a escrita não somente como autor, mas também como leitor. Privilegiar a reflexão, como afirma Neves (2004, p.115), "é exatamente a razão de preconizar um tratamento da gramática que vise ao uso lingüístico”. A autora acrescenta que não só o estudioso, mas também o falante comum e, no caso deste trabalho, o aluno,

conduzido na reflexão sobre o uso da linguagem, vai poder orientarse na utilização eficiente dos recursos do processamento discursivo, e, a partir daí, chegar a uma sistematização dos fatos da língua legitimada pelo efetivo funcionamento da linguagem.

O professor, por sua vez, terá elementos, extraídos da $2^{a}$ versão, para avaliar que aspectos gramaticais o aluno precisa dominar para melhorar a escrita do texto, pois o encaminhamento de uma terceira versão será voltado para o nível micro. Para auxiliar a segunda reescrita, entram em cena as aulas de gramática. O professor sugere, então, exercícios que podem auxiliar a terceira versão do texto do aluno, ou seja, que busquem a expansão do repertório de recursos gramaticais/coesivos, sempre tentando atrelá-los à função no gênero estudado (no caso, a narrativa escolar).

Em uma possível reescrita desse texto, tanto pode predominar a construção de orações coordenadas como subordinadas; estas últimas exigiriam um conhecimento dos conectores interfrásticos e não só da pontuação. Dependendo do objetivo do professor, ele pode apresentar para a classe duas ou mais possibilidades, destacando-se ora elementos como ponto, vírgula, ora conectores que introduzem orações subordinadas.

A partir de exemplos (vindos de atividades de reescrita dos alunos), o professor solicita que os alunos apontem os recursos que os diferenciam, que identifiquem qual a maneira de escrever que apreciam mais. No caso do texto em que prevaleçam as orações coordenadas, o uso dos pontos finais separando as orações, da conjunção aditiva etc. A partir daquele em que se destacam as subordinadas (ainda que não dominem a nomenclatura), perceber a função de cada um no texto 
pode ser um exercício interessante. Depois disso, provavelmente, o aluno estará mais apto a transformar períodos coordenados em subordinados, ou seja, a reescrever trechos de sua redação ou da de um colega, escolhendo quais recursos vai utilizar, apropriando-se de conectivos que a classe possa ter identificado e listado, a partir do exercício anterior.

Outra possibilidade é apresentar um texto sem os conectivos ou a pontuação e pedir para os alunos proporem às frases um encadeamento, atentos sempre aos significados que o autor tentou construir, adicionando elementos coesivos necessários para a construção da coerência. As diferentes respostas podem ser socializadas entre os alunos e comparadas, por último, ao texto original. Caberia também o exercício de reduzir parágrafos com excesso de informações. $O$ aluno grifa as informações e palavras repetidas em determinado trecho e as elimina com o uso de certos conectores estipulados ou não pelo professor, como no exemplo:

Grife no trecho abaixo a informação repetitiva e reescreva-o, eliminando a informação repetitiva e acrescentando pois ou porque:

Um dia eu encontrei um cachorro perto da minha casa eu chorei de dó eu queria que minha mãe levasse ele para casa mas ela não quis. Eu vi o cachorro comendo lixo na lixeira e fiquei com muita vontade de levar ele para minha casa mas minha mãe não deixou.

As informações repetitivas são: a) que a mãe não deixou levar o cachorro para casa, com uso dos verbos quise deixou, respectivamente; b) a vontade de levar o cachorro para casa, com as expressões eu queria que e fiquei com muita vontade de. O trecho também repete exaustivamente c) o substantivo cachorro e d) o pronome ele. Uma resposta possível é:

Um dia eu encontrei um cachorro comendo lixo na lixeira perto da minha casa. Chorei de dó e fiquei com muita vontade de levá-lo para minha casa, mas minha mãe não deixou.

A partir de atividades de gramáticas como essas, o aluno teria mais recursos para trabalhar a segunda reescrita do texto, inclusive maior possibilidade de identificar os problemas e entender os sinais indicativos e os apontamentos feitos pelo professor na correção em nível micro. 
Aposta-se aqui na eficiência da aula de gramática quando se considera o texto em sua completude e quando essa aula se baseia nas atividades de reescrita. Todos os exercícios propostos aqui foram inspirados nos problemas reais da redação da aluna (que espera-se representar problemas recorrentes do grupo de alunos); nesse contexto sua aplicação ganha sentido. Tais exercícios em outro contexto correm o risco de ganhar o mesmo caráter normativo daqueles que estamos criticando. Isso não quer dizer que o professor não deva se apropriar de nenhum exercício pronto no material didático de que dispõe, mas sim alertar que, para a aula de gramática estar a serviço do desenvolvimento da escrita, eles devem ser rigorosamente selecionados, a fim de funcionarem como um recurso em auxílio de se cumprir o objetivo da aula, e não apenas uma atividade para preencher (perder?) o tempo.

Teorizar a gramática separadamente, exemplificando com frases isoladas ou retirando frases de um texto, não garante que o aluno vai incorporar e aplicar o conhecimento. Segundo Ilari (1992, p. 86),

a maior unidade lingüística que a gramática tradicional e muitas orientações da lingüística moderna têm reconhecido é o período, simples ou complexo. Entretanto, existem fenômenos gramaticais que só se explicam quando se levam em consideração unidades mais amplas que o período.

Ilari lembra de alguns conceitos de Halliday, que acredita que "as orações de um texto bem formado assumem normalmente características gramaticais diferentes daquelas que teriam se fossem expressas isoladamente".

Neves (2004, p.125) confirma essa idéia quando diz que "a gramática que o falante aciona para organizar sua linguagem não se esgota em estruturas menores, nem mesmo no período, o qual é limite, apenas, de uma determinada organização estrutural”. Além disso, também diz a autora que "a cada instância da utilização da língua se ativa a gramática e, portanto, a mesma se explicita a partir do uso lingüístico".

\section{Considerações finais}

As considerações apresentadas aqui apontam para a abordagem funcional da gramática: o tópico curricular não precisa mais ser o "ponto gramatical”, mas sim o gênero que desempenha uma função social 
significativa. A partir da escuta, leitura ou escrita de um determinado gênero é que se buscará ensinar recursos gramaticais relevantes e necessários para a compreensão e para o desenvolvimento da escrita desse gênero.

Se o modo tradicional funcionasse, não teríamos tanta incidência de alunos no terceiro grau sem habilidade para escrever de forma eficaz, uma vez que alguém nessa fase do ensino já teve, no mínimo, 11 anos de aulas de língua materna. Por outro lado, no extremo oposto do ensino tradicional, alguns professores que o abominam propiciam a prática de escrita, ou seja, fazem os alunos escreverem a partir de diferentes temas e propostas, mas não fornecem um retorno ao aluno, uma correção adequada do texto. Só escrever redações, sem refazê-las a partir de um encaminhamento devido, não garante o aprimoramento.

Estão às mãos os PCNs para guiar outro caminho. Mudar a prática, porém, parece exigir, antes e além de mudanças estruturais, mudanças de conceitos, de concepção de linguagem, o que significa um percurso complexo e tortuoso. Se tais mudanças parecem impossíveis para quem está atuando no ensino, basta pensar que é bem menos possível as aulas de língua materna continuarem como estão, que é bem menos possível que professores de português e alunos estejam desperdiçando tanto tempo e potencialidade.

Traz uma verdade a frase de Ruiz (2003, p. 242): a "barreira entre teoria e prática tem de ser rompida. (...)". Mas essa não é, segundo a autora, uma questão que cabe somente à academia resolver. Nósprofessores que façamos a nossa parte. A autora (op.cit.) traz à baila conhecidos dizeres: "ainda que (...) no meio do caminho haja uma pedra (...) ainda que nossas escolhas cotidianas nos façam lembrar (...) uma simples, mas grande, verdade: 'Cada um sabe a dor e a delícia de ser o que é" (VELOSO, 1988). Os resultados negativos ("dolorosos") ou positivos ("deliciosos") dos alunos em relação à escrita estarão não totalmente, mas fortemente relacionados à maneira como foi conduzido o ensino pelo professor.

A metodologia de ensino de gramática aliado à produção de texto sugerida neste trabalho pode até não ser a melhor possível (outras idéias hão de vir!), porém é uma tentativa importante de aliar a teoria lingüística sobre o ensino de língua materna à prática docente. 


\section{Bibliografia}

ALVES, R. Conversas com quem gosta de ensinar. Campinas: Papirus, 2000. PERINI, M. A. Sofrendo a Gramática. São Paulo: Ática, 2000.

HALLIDAY, M.A.K. An itroduction to Functional Grammar. Great Britain: Edward Arnold, 1985.

ILARI, R. A lingüistica e o ensino de português. São Paulo: Martins Fontes, 1992.

NEVES, M.H. Que gramática estudar na escola? São Paulo: Contexto,2004.

PARÂMETROS CURRICULARES NACIONAIS. Ensino Fundamental II. Brasília: MEC, 1998.

RUIZ, E. Como se corrige redação na escola. Campinas: Mercado das Letras, 2003.

SCHNEUWLY, Bernard; DOLZ, Joaquim. Os gêneros escolares - das práticas de linguagem aos objetos de ensino. In: SCHNEUWLY, B; DOLZ, J. \& colaboradores. Gêneros orais e escritos na escola. Campinas: Mercado de Letras, 2004.

SIGNORINI, I.; SILVA, W.R.; TORQUATO, C.; MORAES, E.M.M.; ALVES FILHO, F.; PENTEADO, A.E.A.; RUIZ, E. \& BUIN, E. Metodologias de Ensino de Lingua Portuguesa no ciclo II do Ensino Fundamental. Teia do Saber. Pro-Reitoria de Extensão/ Unicamp/ SEE. Aceito para publicação, 2004.

SILVA, W. Gramática no texto injuntivo: investigando o impacto dos PCN. 2004. Dissertação (Mestrado) - IEL/Unicamp.

VELOSO, C. Dom de Iludir. In: VELOSO, Caetano. Meu nome é gol. CD 83684-2. Polygram, 1988. 